\title{
Article \\ Potential Use of Pruning Residues from Avocado Trees as Energy Input in Rural Communities
}

\author{
Raúl Tauro ${ }^{1,2}$, Borja Velázquez-Martí ${ }^{3}{ }^{\oplus}$, Silvina Manrique ${ }^{4}$, Martin Ricker ${ }^{5}{ }^{\circledR}$, René Martínez-Bravo ${ }^{6}{ }^{(}$, \\ Víctor M. Ruiz-García 2,7 ${ }^{\mathbb{D}}$, Saraí Ramos-Vargas ${ }^{7,8} \mathbb{D}^{\mathbb{D}}$, Omar Masera ${ }^{6} \mathbb{D}$, José A. Soria-González ${ }^{9}$ \\ and Cynthia Armendáriz-Arnez ${ }^{1, *}$
}

Citation: Tauro, R.;

Velázquez-Martí, B.; Manrique, S.;

Ricker, M.; Martínez-Bravo, R.;

Ruiz-García, V.M.; Ramos-Vargas, S.; Masera, O.; Soria-González, J.A.; Armendáriz-Arnez, C. Potential Use of Pruning Residues from Avocado Trees as Energy Input in Rural

Communities. Energies 2022, 15, 1715. https://doi.org/10.3390/en15051715

Academic Editors: Dalia Štreimikienè and Mariusz Jerzy Stolarski

Received: 28 December 2021

Accepted: 31 January 2022

Published: 25 February 2022

Publisher's Note: MDPI stays neutral with regard to jurisdictional claims in published maps and institutional affiliations.

Copyright: (C) 2022 by the authors. Licensee MDPI, Basel, Switzerland. This article is an open access article distributed under the terms and conditions of the Creative Commons Attribution (CC BY) license (https:// creativecommons.org/licenses/by/ $4.0 /)$.
1 Escuela Nacional de Estudios Superiores (ENES), Unidad Morelia, Laboratorio de Contaminación y Salud Ambiental, Universidad Nacional Autónoma de México (UNAM), Antigua Carretera a Pátzcuaro 8701, Exhacienda de San José de la Huerta, Morelia 58190, Mexico; rjtauro@gmail.com

2 Consejo Nacional de Ciencia y Tecnología (CONACYT). Av. Insurgentes Sur 1582, Col. Crédito Constructor, Alcaldía Benito Juárez, Mexico City 03940, Mexico; vruiz@cieco.unam.mx

3 Red de Iberomasa, Programa Iberoamericano de Ciencia y Tecnología para el Desarrollo (CYTED), Departamento de Ingeniería Rural y Agroalimentaria, Universitat Politècnica de València, Camino de Vera s/n, 46022 Valencia, Spain; borvemar@dmta.upv.es

4 Red Iberoamericana de Tecnologías de Biomasa y Bioenergía Rural (ReBiBiR-T), Programa Iberoamericano de Ciencia y Tecnología para el Desarrollo (CYTED), Instituto de Investigaciones en Energía No Convencional (INENCO), Consejo Nacional de Investigaciones Científicas y Técnicas (CONICET), Universidad Nacional de Salta (UNSa), Avenida Bolivia 5150, Salta A4408, Argentina; silvina.m.manrique@gmail.com

5 Departamento de Botánica, Circuito Zona Deportiva s/n, Instituto de Biología, Universidad Nacional Autónoma de México (UNAM), Ciudad Universitaria, Alcaldía Coyoacán, Mexico City 04510, Mexico; mricker@ib.unam.mx

6 Laboratorio de Bioenergía, Instituto de Investigaciones en Ecosistemas y Sustentabilidad (IIES), Universidad Nacional Autónoma de México, Antigua Carretera a Pátzcuaro 8701, Morelia 58190, Mexico; redamar@cieco.unam.mx (R.M.-B.); omasera@gmail.com (O.M.)

7 Laboratorio de Innovación y Evaluación en Bioenergía (LINEB), Laboratorio de Bioenergía y Grupo de Innovación Ecotecnológica y Bioenergía (GIEB), Instituto de Investigaciones en Ecosistemas y Sustentabilidad (IIES), Universidad Nacional Autónoma de México (UNAM), Morelia 58190, Mexico; sarv_3@hotmail.com

8 Facultad de Ingeniería (FI), Universidad Nacional Autónoma de México (UNAM), Avenida Universidad 3000 , Ciudad Universitaria, Mexico City 04510, Mexico

9 Facultad de Ingeniería en Tecnología de la Madera, Universidad Michoacana de San Nicolás de Hidalgo (UMSNH), Morelia 58040, Mexico; jasgsoria@gmail.com

* Correspondence: cynthia_armendariz@enesmorelia.unam.mx

Abstract: The global need to transition to renewable and decentralized systems entails agricultural systems as producers of residual biomass. Avocado trees (Persea americana Mill.) are one of the main woody crops cultivated in Mexico, with over 150,000 hectares grown in the country. The aim of the present study is to evaluate the use of avocado pruning residues as an energy input, focusing on the revalorization of biomass and the generation of economic benefits for small producers in the region. For that purpose, we developed allometric equations to calculate biomass availability from pruning residues, evaluated their thermochemical properties, and proposed technological alternatives for their energy use. Two allometric equations for pruning residues as a function of tree height and crown diameter were obtained: one for light and minor maintenance pruning $\left(R^{2}=0.63\right)$ and one for rejuvenation pruning $\left(R^{2}=0.86\right)$. From these equations, we estimate the mean amount of biomass generated from light and rejuvenation pruning to be 42.7 and $25.1 \mathrm{~kg}$ per tree and year, respectively, which amounts to 1324 and $780 \mathrm{~kg} \mathrm{ha}^{-1} \mathrm{DM}$ (dry matter), with an energy potential of 26.2 and $15.4 \mathrm{GJ} \mathrm{ha}^{-1}$. The thermochemical analysis shows that a higher proportion of leaves generates a higher ash content, which reduces the quality of the residues as a fuel. Avocado pruning residues have high potential for energy use and could be implemented in the industrial and residential sectors, generating a complementary source of income for producers.

Keywords: energy transition; pruning residues; avocado; biomass; rural communities 


\section{Introduction}

Agricultural systems have high potential to produce biomass for energy purposes, which can mitigate our current dependence on fossil fuels. This use of biomass to substitute fossil fuels can also reduce greenhouse gas emissions, especially when it comes from agricultural residues and does not compete with food production [1] or additional land use. Furthermore, it represents an opportunity to complement agricultural rents and stimulate rural development [2]. Implementing an efficient system for biomass energy use entails a detailed technical, economic, and environmental analysis in order to ensure it can be sustainably managed.

For the case of Mexico, Tauro et al. [1] demonstrated that pruning residues from fruit trees have a high potential for energy use in the residential and industrial sectors, substituting fossil fuels and mitigating the emissions of polluting gases. One of the most important fruit tree crops in Mexico is avocado (Persea americana Mill.). In 2018, more than 2 million tons of avocado were grown in Mexico, making it the main producer, consumer, and exporter nation [3]. Most of this production (80\%) comes from the state of Michoacán, where more than 150,000 hectares is dedicated to this crop. An important amount of residual biomass is generated from pruning activities.

Consequently, it is of interest to quantify the amount of generated biomass and analyze the life cycle of avocado pruning residues in order to increase our knowledge of this abundant and periodic resource, which should be managed effectively and can be used for energy purposes. Recent research has focused on quantifying residual biomass from different systems, mainly in the forestry sector [4]. For agriculture, Velázquez-Martí et al. [5-7] quantified residual biomass from grapevine, olive, and almond trees in Mediterranean ecosystems. These authors obtained predictive equations from regression models using easily measurable parameters, such as plant height, trunk diameter, and crown diameter. Other studies have developed more sophisticated techniques using teledetection through spectral images and Lidar technology (see, for example, $[8,9]$ ).

While dendrometric techniques have not often been applied in agriculture due to the limited interest in their energy use, fruit tree pruning residues have been analyzed from different perspectives: Velázquez-Martí and Fernández-González [10] compared the costs of mechanical and hand pruning of citric crops, determining the amount of generated residual biomass, as well as its influence on fruit production and quality. Velázquez-Martí et al. [7] and Velázquez-Martí et al. [11] quantified residual biomass from almond and citric pruning residues in the Mediterranean coast of Europe. Finally, Velázquez-Martí and Cazco-Logroño [2] developed a method for estimating biomass from tree pruning residues in Ecuador using dendrometric equations in regression models.

The potential energy use of avocado in Mexico has not been widely studied, despite it being an abundant crop with a growing demand. In a recent review, García-Vargas et al. [12] presented the current state of research on energy use of avocado residues at the global level. Most of the cited studies focus on the use of avocado pits and rinds generated from the avocado industry for the production of liquid and gas biofuels without accounting for pruning residues, which are burned in orchards. To date, no studies have quantified biomass from avocado tree pruning residues or analyzed its potential for energy use.

The aim of the present study is to evaluate the potential for energy use of avocado pruning residues and assess their potential to generate additional income for local producers. We analyze the amount of available biomass based on the specific characteristics of pruned trees, explore the thermochemical properties of these materials as solid biofuels, and propose different end uses. We quantify biomass by developing equations that can predict the amount of residual biomass from pruning operations using easily obtained tree measurements. Knowing the number of cultivated hectares and the type of pruning used, our methodology will allow the estimation of biomass that is available for potential energy use in a given community or region. Quantifying the amount of biomass that can be obtained from each tree through allometric equations will open the door for future studies on tree growth and territorial energy planning, benefiting both the users and the owners of biomass. 


\section{Materials and Methods}

\subsection{Study Site}

The municipality of Tingambato is located in the northern portion of the state of Michoacán. It has an area of 18,990 ha and represents $0.32 \%$ of the state's surface. The mean elevation is $1898 \mathrm{~m}$ above sea level, and the maximum elevation is $1980 \mathrm{~m}$. It has a population of about 15,000 people. The climate is temperate, with a mean annual temperature of $16^{\circ} \mathrm{C}$ and a mean annual rainfall of $1000-1100 \mathrm{~mm}$, with rains occurring mostly from June to September. The predominant soil groups are andosol $(74.4 \%)$, lithosol $(8.8 \%)$, vertisol $(8.0 \%)$, luvisol $(3.4 \%)$, and phaeozem $(2.9 \%)$, with the remaining $2.1 \%$ made up of other types (acrisol, regosol, and cambisol). The prevailing land use is agriculture of perennial crops, such as avocado, and to, a lesser extent, forestry activities with pine and oak species.

About $4 \%$ of Mexico's avocado production comes from Tingambato. The Hass variety dominates, representing $95 \%$ of the region's production [3]. Currently, 4250 ha is cultivated each year [3] in orchards registered at the Local Board of Agricultural Health of Tingambato (JLSV for its Spanish acronym). Most of them are destined for export. Out of the registered orchards, 3\% are organic certified, while the rest are conventional orchards. Trees are spaced at 10 to $12 \mathrm{~m}$, with a mean density of 100 trees per hectare. The tree spacing allows machines to carry out agricultural tasks. This arrangement would also be advantageous for harvesting pruning residues.

Orchard management activities include pruning, which is carried out after the harvest and before flowering. Pruning increases fruit production, improves tree health, and maintains an adequate plant size that facilitates harvest and efficient pesticide application. Although there is no official classification for pruning methods, three different types can be identified based on their intensity. Hard pruning or renewal or rejuvenation pruning is carried out on average every 10 years and consists of fully cutting down the crown, or even the entire tree, when the plant is infested or when completely renewing the orchard. Maintenance or tree shape pruning is an annual method that consists of eliminating central or lateral branches, allowing more light to enter through the crown, diminishing the probability of becoming infested, and increasing tree productivity. Light maintenance pruning is also carried out yearly, with the objective of removing smaller branches to maintain the tree's height and shape.

From the residues generated through pruning, the smaller branches (generally with diameters under $2.5 \mathrm{~cm}$ ) that contain leaves are ground and incorporated into the soil. Branches with bigger diameters do not have an established use; a large percentage is burned in the field, while the rest is given away or sold at a low price in the informal market, mainly for constructing transportation boxes. Pruning residues from organic orchards are used as firewood by nearby households.

\subsection{Collection of Samples}

We randomly selected 56 trees from a subset of 10 avocado orchards based on technical criteria provided by the producers or owners of the orchards. We measured their allometric variables and weighted their pruning residues. The age range of the orchards in our sample was between 12 and 70 years, and they varied in size from 3 to 60 ha. All employed a drip irrigation system. We distinguished intensive rejuvenation pruning, intensive tree shape pruning, and light pruning and estimated the amount of biomass generated from each of the three types of pruning.

After pruning, the residues were bundled into sheaves and weighted using a digital dynamometer with a maximum load capacity of $250 \mathrm{~kg}$. The sheaves were assembled by separating the smaller-diameter branches with leaves, which are mainly incorporated into the soil at the orchards, and the larger branches with no leaves, which have the potential of being used for energy generation.

In order to determine the fraction of leafy and woody biomass, we selected the branches of five trees from our sample (from different orchards and with different ages and dimensions) and measured their initial weight with leaves before removing the leaves 
and reweighting. The percentage of woody biomass $\left(B_{w}\right)$ was calculated with Equation (1), and the percentage of leafy biomass $\left(B_{l}\right)$ was obtained from Equation (2), where $m_{l}$ is the biomass of branches with leaves and $m_{w}$ is the biomass with no leaves.

$$
\begin{gathered}
B_{w}=\frac{m_{l}}{m_{w}} 100 \% \\
B_{l}=B_{w}-100 \%
\end{gathered}
$$

\subsection{Measuring Residual Biomass with a Destructive Method}

The first step was to define the characteristics of the sampled trees before pruning Following Velázquez-Martí et al. [5], we considered the main variables: type of pruning method, orchard age (later classified into age ranges), time of last pruning, and orchard size. In order to relate tree characteristics to the amount of generated pruning residues, we measured the following variables before pruning: tree trunk diameter $(D t)$ at the height of the first branch, total tree height $(H)$, crown height $(H c)$, and crown diameter $(D c)$. We used a measuring tape or a vernier caliper to obtain $D t$ and $D c$. To measure $H$, we used a measuring tape or a Nikon Forestry Pro hypsometer when the height surpassed $5 \mathrm{~m}$. $H c$ was calculated as the difference between total tree height and the height at the first branching point.

To be able to estimate the amount of generated biomass per tree and year as a function of measured tree variables, two allometric equations were derived through multiple linear regression with ordinary least squares (e.g., [13], chapter 16). The first equation is for light to intensive pruning, and the second for the much more rigorous rejuvenation pruning. All calculations were carried out in a Mathematica notebook (https: / www.wolfram.com/ mathematica/ accessed on 30 January 2022). Manly's exponential transformation was employed for the dependent variable (harvested biomass from pruning), with Ricker's approach to eliminate skewness of the transformed lumped residuals. For details on the formulas and the algorithm to derive the optimal parameter, see [14].

Correlation coefficients and ANOVAs were calculated first to understand the variation and relationships within the data (without transformation). Pearson correlation coefficients above 0.5 were considered high (without testing for statistical significance, which would add assumptions). Subsequently, a number of regression models, including curvilinear ones, were examined. The significance of the regression coefficients and partial residual plots were used as criteria for judging the model quality.

\subsection{Determining the Thermochemical Properties of Pruning Residues}

\section{- Sample Preparation}

Samples were obtained from 10 recently pruned trees. Biomass components were classified into three categories: branches, branches with leaves, and leaves. We selected leafy branches with diameters less than $2.5 \mathrm{~cm}$ and an approximate length of $10 \mathrm{~cm}$ (these represent about 55\% of the average weight) and branches without leaves with diameters greater than $2.5 \mathrm{~cm}$ and a length of $10 \mathrm{~cm}$ (45\% of the measured weight). The aim of separating leaves and branches was to identify the difference in ash properties and contents between the two samples. The samples were transported in hermetically sealed bags. Once in the laboratory, they were dried outdoors and milled with an FS-LL Mill (Lab Whirlwind, Hangzhou, China). Analysis was performed with samples containing particles of mesh sizes $40(0.42 \mathrm{~mm})$ and $60(0.25 \mathrm{~mm})$. The differences in the mean for individual characteristics between branches, leaves, and branches with leaves were tested using one-way ANOVA. Characteristics were obtained as follows:

\section{- Moisture content}

The percentage moisture content $(\mathrm{M})$ was determined three times for each sample $(n=3)$ immediately after collection. We followed the EN ISO 18134-1 [15] standard and 
used an enameled steel drying oven (HS60-ED, Enameled Steel Drying Oven, Novatech, Tlaquepaque, Mexico).

- Proximate analysis

We estimated the percentage of ash content following the UNE-EN ISO 18122 [16] standard and of volatile matter following the guidelines established in ASTM E872-82 [17]. We used a Novatech MD-20 mufflefurnance and an EX225D semimicro analytical balance (Ohaus, NJ, USA) for both analyses. We used a mesh size of 40 for the biomass particle size previously dried in an HS60-ED oven (Novatech, Tlaquepaque, Mexico). The fixed carbon percentage was calculated by subtracting the ash and volatile matter contents from the sample in anhydrous state [18]. Values were determined three times for each sample $(n=3)$.

- Elemental analysis

The percentages of carbon $(\mathrm{C})$, nitrogen $(\mathrm{N})$, and sulfur $(\mathrm{S})$ were obtained from biomass powder in an organic elemental analyzer (Thermo Scientific Flash 2000, Colorado Springs, Waltham, MA, USA) using a modified Dumas method [19] and the "Eager Xperience" software for data processing. Values were duplicated for each sample $(n=2)$.

- Calorific value

We measured the superior calorific value (HHV) with a Parr 6100 (Molin, IL, USA) compensated jacket-bomb calorimeter and a method outlined in UNE-EN ISO 18125 [20]. The calorimeter was verified using sodium benzoate standards. Values were determined three times for each sample $(n=3)$.

\subsection{Energy Potential and End Uses}

With the results from the statistical analysis described above, we extrapolated the amount of generated biomass to the per-hectare scale. Multiplying this by the biomass's calorific value allows us to estimate the specific energy potential for each type of pruning method and, hence, the potential biomass available for energy uses per hectare.

The energy properties of pruning residues were compared with other types of biomass using a quality index. Based on the quality values obtained, we then suggest different end uses among common applications in the local residential and small to medium industry sectors. We calculated a biomass quality index (BQI) with the results obtained from the thermochemical analysis of pruning residues (Section 2.4) as a reference about their quality as a solid biofuel. The index is based on the methods developed by Cherney and Verma [21], who proposed a pellet quality index for domestic uses, and the adaptation by Rocha et al. [22] to determine the BQI for different types of biomass.

First, the most relevant parameters to be measured and compared were selected according to Vasileiadou et al. [23]. Then a quality index (PQI) for each evaluated parameter was determined based on reference values. Table 1 shows the chosen parameters, associated with their quality as solid biofuels, together with their respective reference values according to Cherney and Verma, and Rocha et al. [21,22], which were selected based on the chemical properties of different types of biomass.

Table 1. Parameters that affect biomass quality and their value ranges.

\begin{tabular}{cccccc}
\hline No. & Parameter & Units & $\begin{array}{c}\text { Threshold Value } \\
\left(x_{\text {threshold }}\right)\end{array}$ & $\begin{array}{c}\text { Optimal Value } \\
\left(x_{\text {optimal }}\right)\end{array}$ & Reference \\
\hline 1 & Moisture & $\% w t$ & 20 & 12 & \\
2 & Ash & $\% w t$ & 3.0 & 0.7 & \\
3 & $\mathrm{C}$ & $\% w t$ & 49 & 60 & [21,22] \\
4 & $\mathrm{HHV}$ & $\mathrm{MJ} \mathrm{kg}^{-1}$ & 14.5 & 22 & \\
\hline
\end{tabular}


Table 1. Cont.

\begin{tabular}{cccccc}
\hline No. & Parameter & Units & $\begin{array}{c}\text { Threshold Value } \\
\left(x_{\text {threshold }}\right)\end{array}$ & $\begin{array}{c}\text { Optimal Value } \\
\left(x_{\text {optimal }}\right)\end{array}$ & Reference \\
\hline 5 & $\mathrm{~N}$ & $\% \mathrm{wt}$ & 1.5 & 0.1 \\
6 & $\mathrm{~S}$ & $\% \mathrm{wt}$ & 0.2 & 0.04 \\
\hline
\end{tabular}

The formula used to obtain the PQI [22] is:

$$
P Q I=\left(\frac{x_{\text {measured }}-x_{\text {optimal }}}{x_{\text {threshold }}-x_{\text {optimal }}}\right)
$$

where $x_{\text {measured }}$ is the measured value of parameter $i, x_{\text {optimal }}$ is the optimal value for each parameter, and $x_{\text {threshold }}$ is the maximum or minimum value for each parameter within the working range. The optimal, maximum, and minimum values from the literature are given in Table 1.

Following Rocha et al. [22], the formula to calculate the BQI is

$$
B Q I=\sum_{i=1}^{6} P Q I_{i}
$$

where $B Q I$ is the quality index for the residual biomass, which is the sum of the $P Q I$ of each of the six parameters evaluated in Table 1. A lower index represents a higher quality of the biomass as fuel. Once the BQIs for the pruning residues were obtained, we compared them with the reference values in [23], who used the values from Table 1 to estimate the BQI of different agricultural residues.

The moisture content greatly influences the quality index. The $B Q I$ has been reported for varying moisture contents [22], as well as dry conditions [23], showing a negative correlation between moisture content and $P Q I$ and, therefore, also the BQI. Hence, we performed a sensitivity analysis to indicate the influence of moisture content on the final quality of avocado pruning residues by changing moisture content values while holding other parameters constant. In order to produce a practical and reproducible result at the orchard level, the mean energy properties for all pruning residues regardless of the type of pruning were considered.

\section{Results and Discussion}

\subsection{Allometric Analysis}

First, we tested for significant mean differences among groups of data. Analysis of variance (ANOVA) of the log-transformed pruned biomass for all three pruning types combined revealed highly significant differences in mean mass among the 10 orchards, 13 agegroups (from 7 to 70 years old), and 4 periods since the last pruning. These variables, however, are correlated with the structural variables that are used below in the allometric equations:

(a) Periods since the last pruning is correlated with tree crown diameter (Pearson correlation coefficient of 0.60 );

(b) Mean pruned mass per plantation is highly correlated with crown diameter (0.65), as well as with total tree height (0.60);

(c) Somewhat surprisingly, tree age is not particularly correlated with any variable, including pruned mass; this makes it uninteresting for inclusion.

Subsequently, two allometric equations were obtained from the pruning residue data of 56 individual trees obtained from 10 avocado orchards. Regression analysis for the three types of pruning revealed no relevant differences of allometric relationships between the light and intensive methods so that the data of these two types of pruning were lumped; this increased the sample size and made the model more robust. There was, however, a large difference between this joint group and the much more rigorous rejuvenation pruning. 
Table 2 shows the two separate equations obtained, together with the corresponding statistical information for each pruning-type group.

Table 2. Allometric equations from ordinary least squares (OLS) regression.

\begin{tabular}{|c|c|c|}
\hline & Light to Intensive Pruning & Rejuvenation Pruning \\
\hline Regression equation & $\begin{array}{l}\hat{M}=-173.65 \\
\ln \left[\begin{array}{l}1.3820 \\
-0.035553 \cdot D_{c} \\
-0.049292 \cdot H_{t}\end{array}\right.\end{array}$ & $\begin{array}{l}\hat{M}=-159.87 \\
\ln \left[\begin{array}{l}1.1981 \\
-0.033055 \cdot D_{c} \\
-0.081524 \cdot H_{t}\end{array}\right.\end{array}$ \\
\hline $\begin{array}{l}\text { Regression results with } \\
\text { transformed dependent } \\
\text { variable }(M)\end{array}$ & $\begin{array}{l}n=46, R_{a d j}^{2}=0.63 \\
\lambda=-0.00576 \\
P\left(Y_{0}\right)=7 \cdot 10^{-6} \\
P\left(D_{c}\right)=2 \cdot 10^{-6} \\
P\left(H_{t}\right)=2 \cdot 10^{-4} \\
r\left[D_{c}, H_{t}\right]=0.41\end{array}$ & $\begin{array}{c}n=10, R_{a d j}^{2}=0.86, \\
\lambda=-0.00625, P\left(Y_{0}\right)=0.2, \\
P\left(D_{c}\right)=0.06 \\
P\left(H_{t}\right)=3 \cdot 10^{-4}, \\
r\left[D_{c}, H_{t}\right]=0.27\end{array}$ \\
\hline Applicable range & $\begin{array}{c}3.4 \leq D_{c} \leq 14.2 \mathrm{~m} \\
3.4 \leq H_{t} \leq 10 \mathrm{~m}\end{array}$ & $\begin{array}{c}7.1 \leq D_{c} \leq 10.6 \mathrm{~m} \\
5.8 \leq H_{t} \leq 10 \mathrm{~m}\end{array}$ \\
\hline Mean parameters & $\overline{D_{c}}=8.17 \mathrm{~m}, \overline{H_{t}}=6.28 \mathrm{~m}$ & $\overline{D_{c}}=8.96 \mathrm{~m}, \overline{H_{t}}=7.27 \mathrm{~m}$ \\
\hline $\begin{array}{l}\text { Expected mass at } \\
\text { mean parameters }\end{array}$ & $42.7 \mathrm{~kg}$ & $187.7 \mathrm{~kg}$ \\
\hline $95 \%$ confidence interval & 36.6 to $49.1 \mathrm{~kg}$ & 171.2 to $206.1 \mathrm{~kg}$ \\
\hline $\begin{array}{l}\text { Residuals from mean } \\
\text { without regression }\end{array}$ & $\begin{array}{c}\text { Total range: }-42.7 \text { to } 89.4 \mathrm{~kg} \text {, } \\
\text { interquartile range: }-33.2 \text { to } \\
25.6 \mathrm{~kg} \text {, standard deviation: } \\
\quad 39.0 \mathrm{~kg}\end{array}$ & $\begin{array}{c}\text { Total range: }-103.2 \text { to } \\
261.6 \mathrm{~kg} \text {, interquartile range: } \\
-74.9 \text { to }-24.0 \mathrm{~kg} \text {, standard } \\
\text { deviation: } 128.6 \mathrm{~kg}\end{array}$ \\
\hline $\begin{array}{l}\text { Residuals from OLS } \\
\text { regression after } \\
\text { back-transformation }\end{array}$ & $\begin{array}{l}\text { Total range: }-44.5 \text { to } 67.5 \mathrm{~kg} \text {, } \\
\text { interquartile range: }-15.0 \text { to } \\
13.5 \mathrm{~kg} \text {, standard deviation: } \\
22.4 \mathrm{~kg}\end{array}$ & $\begin{array}{l}\text { Total range: }-26.7 \text { to } 63.4 \mathrm{~kg} \text {, } \\
\text { interquartile range: }-18.6 \text { to } \\
24.5 \mathrm{~kg} \text {, standard deviation: } \\
28.0 \mathrm{~kg}\end{array}$ \\
\hline $\begin{array}{l}\text { Reduction of residuals } \\
\text { with regression }\end{array}$ & $\begin{array}{c}\text { Total range: }-20.2 \mathrm{~kg} \\
(-15.3 \%), \text { interquartile range: } \\
-30.3 \mathrm{~kg}(-51.6 \%)\end{array}$ & $\begin{array}{c}\text { Total range: }-274.6 \mathrm{~kg} \\
(-75.3 \%), \text { interquartile range: } \\
-7.9 \mathrm{~kg}(-15.4 \%)\end{array}$ \\
\hline \multicolumn{3}{|c|}{$\begin{array}{l}\overline{D_{c}}=\text { tree crown diameter }(\mathrm{m}) ; H_{t}=\text { total tree height }(\mathrm{m}) ; D_{c} \text { and } H_{t} \text { mean value of all data points of the variables } \\
\overline{D_{c}} \text { and } \overline{H_{t}} \text {, respectively; } \lambda=\text { parameter lambda of Manly's exponential data transformation that is optimized to } \\
\text { eliminate skewness of the lumped residuals; } \ln =\text { natural logarithm; } M=\text { measured harvested mass from pruning } \\
(\mathrm{kg}) ; \hat{M}=\text { predicted mean harvested mass }(\mathrm{kg}) ; n=\text { number of data points; } P\left(Y_{0}\right), P\left(D_{c}\right) \text {, and } P\left(H_{t}\right)=\text { probabilities } \\
\text { that the expected values of the Y-intercept and the slopes of the variables } D_{c} \text { and } H_{t} \text { are zero; } r\left[D_{c}, H_{t}\right]=\text { Pearson } \\
\text { correlation coefficient between the variables } D_{c} \text { and } H_{t} ; R_{a d j}^{2}=\text { coefficient of determination, adjusted for the number } \\
\text { of variables. }\end{array}$} \\
\hline
\end{tabular}

- $\quad$ Light to intensive pruning:

As expected, we found a high correlation between tree crown diameter and trunk diameter (0.67) and between total tree height and height at the first branch (0.89). Crown diameter is considerably more highly correlated with pruned weight, and total tree height is easier to identify than the height up to the crown. To avoid the typical problems of collinearity in regression, only crown diameter and total tree height were included as explanatory variables for harvested mass from pruning. One abnormally large tree in the light pruning treatment was excluded as an outlier.

- Rejuvenation pruning:

With only 10 data points, statistical analysis is less telling and less robust. The Pearson correlation coefficient between crown diameter and trunk diameter is only 0.09 , which is also due to a relatively small data range. The correlation coefficient between total tree height and height up to the crown, however, is very high (0.98). None of the above-mentioned ANOVAs are significant. The same regression model as before, however, resulted in a 
plausible regression equation, where the regression coefficient of total tree height is highly significant, and the one for crown diameter is marginally significant (at the $5 \%$ level).

The still relatively large dispersion of the regression residuals may be due to a number of factors that determine the amount of harvested biomass per tree (Table 2). Although all orchards in our sample use drip irrigation systems, we do not have data on water volume per tree; differences in amount of water used per day or number of irrigation days per year may explain some of the variation in our data. The same could be said about fertilizer type, root biomass, leaf strata in the tree canopy, edaphic factors such as soil type and quality, or even ecological factors, such as geographical exposure, slope, and altitude. These variables may affect tree productivity and, in consequence, the amount of biomass obtained from pruning.

Our results show that pruning management is related to the size of the tree and not to the type of orchard. In other words, there is no correlation between the sampled orchard and the applied type of pruning. In some orchards, two types of pruning were carried out in parallel according to the needs of each tree, while under more controlled management or in smaller parcels, only one type of pruning was observed.

\subsection{Residual Biomass}

At mean parameters for crown diameter and tree height, the allometric equations of Table 2 result in a mean biomass of $42.7 \mathrm{~kg}_{\text {tree-year }}{ }^{-1}$ from light to intensive pruning and $187.7 \mathrm{~kg}$ per tree for rejuvenation pruning. Considering that rejuvenation pruning is carried out on average every 7.5 years, we obtain an annual biomass value of $25.1 \mathrm{~kg}$ tree-year $^{-1}$.

These results are in line with previous findings by Paniagua et al. [24], who determined that the amount of biomass obtained from pruning Hass avocado trees in Malaga (Spain) was 50 to $75 \mathrm{~kg}$ per tree, whereas the Bacon variety produced between 200 and $300 \mathrm{~kg}$ tree. When considering that the mean moisture content of the freshly harvested biomass is $69 \%$ (see next section), we obtain $13.24 \mathrm{~kg}$ of dried matter $\left(\mathrm{kg}\right.$ tree $\left.{ }^{-1} \mathrm{DM}\right)$ and $7.80 \mathrm{~kg}$ tree $^{-1}$ $\mathrm{DM}$ for the light to intensive and rejuvenation pruning method. Considering an average of 100 trees per hectare, this yields 1324 and $780 \mathrm{~kg} \mathrm{ha}^{-1} \mathrm{DM}$, respectively.

Table 3 shows the results obtained by studies with similar methodologies for fruit tree crops in different parts of the world. While the harvested biomass from avocado pruning residues per hectare in our study covers a wide range, depending on the type of pruning and other biophysical variables, it is consistent with the ranges presented in the table. The per-tree biomass values, however, are higher than those shown in the table. This is probably due to differences in tree density, which are much higher for the crops included in the table (580 trees on average).

Table 3. Comparison of amounts of residual biomass generated from different types of crops.

\begin{tabular}{|c|c|c|c|}
\hline Crop & $\begin{array}{c}\text { Annual Biomass per } \\
\begin{array}{c}\text { Hectare } \\
\left(\mathrm{kg} \mathrm{ha}^{-1}\right) *\end{array}\end{array}$ & $\begin{array}{l}\text { Biomass per Tree } \\
\left(\mathrm{kg}^{\left.- \text {rbol }^{-1}\right)}{ }^{*}\right.\end{array}$ & Reference \\
\hline $\begin{array}{c}\text { Citrus trees } \\
\text { (mechanical pruning) }\end{array}$ & 1360 & 2.3 & \\
\hline $\begin{array}{c}\text { Citrus trees } \\
\text { (post-mechanical } \\
\text { manual pruning) }\end{array}$ & 2316 & 4.8 & [11] \\
\hline $\begin{array}{l}\text { Citrus trees } \\
\text { (traditional pruning) }\end{array}$ & 3516 & 5.9 & \\
\hline Almond tree & 1340 ** & $12.6-3.5$ & [5] \\
\hline
\end{tabular}


Table 3. Cont.

\begin{tabular}{|c|c|c|c|}
\hline Crop & $\begin{array}{c}\text { Annual Biomass per } \\
\text { Hectare } \\
\left(\mathrm{kg} \mathrm{ha}^{-1}\right) *\end{array}$ & $\begin{array}{l}\text { Biomass per Tree } \\
\left(\mathrm{kg} \text { árbol }^{-1}\right)^{*}\end{array}$ & Reference \\
\hline $\begin{array}{l}\text { Citrus trees (orange } \\
\text { Valencia Late) }\end{array}$ & 4700 & 9.4 & \multirow{6}{*}{ [11] } \\
\hline $\begin{array}{c}\text { Citrus trees (orange } \\
\text { Naveline) }\end{array}$ & 2970 & 5.4 & \\
\hline $\begin{array}{l}\text { Citrus trees (orange } \\
\text { N. Washington) }\end{array}$ & 2400 & 4.1 & \\
\hline $\begin{array}{l}\text { Citrus trees } \\
\text { (mandarin } \\
\text { Clementine) }\end{array}$ & 3490 & 5.1 & \\
\hline $\begin{array}{c}\text { Citrus trees } \\
\text { (mandarin Hybrid) }\end{array}$ & 4050 & 5.1 & \\
\hline $\begin{array}{c}\text { Citrus trees } \\
\text { (mandarin Satsuma) }\end{array}$ & 3330 & 4.9 & \\
\hline Ciruelo (plum trees) & $2000 \pm 800$ & $2.34 \pm 0.97$ & [2] \\
\hline
\end{tabular}

The equations developed here allow us to estimate the amount of biomass generated from pruning different-sized trees; however, they are valid only for a certain range of allometric dimensions, and therefore, it is not possible to extrapolate to all orchards. For this, it would be necessary to sample a greater number of trees and orchards in order to obtain a more representative equation for a variety of orchard management systems. The results obtained could then be validated with biomass measurements taken directly from the field.

\subsection{Thermochemical Properties of Pruning Residues}

Table 4 details the results of the elemental and energetic analyses from the samples (branches, leaves, and branches with leaves) and the initial moisture content. Although there are significant differences in the experimental design, these differences do not affect the practical approach of this work.

Table 4. Thermochemical characteristics of the pruning residue samples (values in dry matter).

\begin{tabular}{|c|c|c|c|c|c|c|c|}
\hline \multirow{2}{*}{ Parameter } & \multicolumn{2}{|c|}{ Branches } & \multicolumn{2}{|c|}{ Leaves } & \multicolumn{2}{|c|}{ Branches with Leaves } & \multirow{2}{*}{ ANOVA } \\
\hline & Mean & SD & Mean & SD & Mean & SD & \\
\hline $\mathrm{HHV}\left(\mathrm{MJ} \mathrm{kg}^{-1}\right)$ & 19.7 & 0.1 & 20.1 & 0.1 & 19.7 & 0.1 & $\mathrm{~F}=10.11$, d.f. $=2, \mathrm{P}=0.012$ \\
\hline Moisture content (\%) & 69.7 & 1.2 & 63.3 & 0.2 & 73.6 & 0.6 & $\mathrm{~F}=121.6$, d.f. $=2, \mathrm{P}=0.000001$ \\
\hline Ash content $(\%)$ & 3.4 & 0.1 & 6.9 & 0.5 & 6.3 & 0.2 & $\mathrm{~F}=1148$, d.f. $=2, \mathrm{P}=0.000000017$ \\
\hline Volatile matter $(\%)$ & 88.1 & 0.6 & 81.7 & 0.7 & 79.9 & 0.5 & $\mathrm{~F}=122.1$, d.f. $=2, \mathrm{P}=0.0000138$ \\
\hline Fixed carbon $(\%)$ & 8.4 & 0.4 & 10.8 & 0.3 & 12.4 & 0.3 & $\mathrm{~F}=35.14$, d.f. $=2, \mathrm{P}=0.000487$ \\
\hline$C(\%)$ & 46.5 & 2.1 & 45.7 & 1.6 & 47.1 & 0.1 & NA \\
\hline $\mathrm{N}(\%)$ & 0.5 & 0.1 & 2.6 & 0.3 & 2.2 & 0.1 & NA \\
\hline $\mathrm{S}(\%)$ & $<0.01$ & NA & 0.16 & 0.01 & 0.13 & 0.01 & NA \\
\hline
\end{tabular}

NA: not applicable. Sulfur content for branches is below the detection limit for the equipment used. $\mathrm{F}=$ ratio $\mathrm{P}=$ value test; d.f. = degree freedom. All means are in dry matter. The remarked values show the significant differences between different classifications of the tree after a Tukey test.

Freshly harvested samples' moisture content ranged from $63 \%$ to $73 \%$, which is considered high. In order for this type of biomass to be useful as a fuel or as an input for producing desiccated fuels, their moisture content must be significantly reduced through some form of drying process. Moisture content $(\mathrm{M})$ for firewood has been estimated to be 
at $11 \pm 2 \%$ in the field [25] and $7 \pm 1 \%$ in the laboratory [26]. Moisture content of pellets must not exceed $10 \%$ [27], while for woodchips it is expected to be below $30 \%$.

The mean ash content for the samples was different for branches $(3.4 \%)$, leaves $(6.9 \%)$, and branches with leaves $(6.3 \%)$. The presence of leaves generates a greater percentage of ash content, which reduces the quality of pruning residues as an energy source, because it lowers the calorific value and may cause technical problems in the burner or boiler. The values reported here are in line with previous findings for tropical woods $[18,28]$.

Regarding volatile matter content, we obtained values of $88.1 \pm 0.6 \%$ in branches and $81.7 \pm 0.7 \%$ in leaves. This value refers to the fraction of biomass that is transformed into gas during the combustion process [29]. These values generally align with those reported for tropical woods [18] but are greater than those reported by García-Vargas [12] for avocado leaves. Here, the fixed carbon percentage obtained was $8.4 \pm 0.4 \%$ in branches and $12.4 \pm 0.3 \%$ in branches with leaves. Fixed carbon refers to the oxidative fraction in the solid phase of biomass and is greater when using both branches and leaves as a fuel, as determined by [29].

The percentage of carbon obtained is similar to values reported in other studies [18,30-32]. For nitrogen and sulfur, we found lower percentages in branches than in leaves and in branches with leaves. Given the relatively lower values for $\mathrm{N}$ and $\mathrm{S}$ in branches, we expect that when used as a biofuel, they will emit low amounts of sulfur dioxide $\left(\mathrm{SO}_{2}\right)$, nitrogen oxides $\left(\mathrm{NO}_{\mathrm{x}}\right)$, and nitrous oxide $\left(\mathrm{N}_{2} \mathrm{O}\right)$ [33]. The sulfur content associated with the organic part of biomass is considered to be emitted at low temperatures, while inorganic sulfur makes up part of the ash [34].

Moisture content is inversely proportional to the calorific value (HHV). Hence, although the moisture content is higher in small-diameter branches where leaves dominate, the HHV remains constant across our samples. The greater HHV found in leaves may be due to the presence of flowers and small fruits in some of the samples collected, and contrasts with the increased ash content. The mean HHV for the three types of biomass samples is $19.8 \mathrm{MJ} \mathrm{kg}^{-1}$, which corresponds to energy values reported for forestry species and specifically to the value of $19.4 \mathrm{MJ} \mathrm{kg}^{-1}$ obtained for Hass and Bacon avocado pruning residues in [24]. According to this parameter, pruning residues have excellent energy-use characteristics. Considering the HHV values obtained (Table 4), the energy potential per area unit could range from 26.2 to $15.4 \mathrm{GJ} \mathrm{ha}^{-1}$.

\subsection{Energy Potential, Sensitivity Analysis, and End Uses}

Figure 1 shows a comparison among the quality indices obtained for avocado pruning residues and the reference values for other biomass types (Vasileiadou et al., 2021), considering a moisture content of $10 \%$ in all cases. Avocado tree branches (firewood) have a higher energy quality than leaves and branches with leaves according to the parameters selected in this study (BQI 2.56). Although it is a woody residue, the energy characteristics of the branches resemble those of corn stubble and nut shells (Figure 1), which may be due to their low sulfur content and high calorific value, respectively. These properties make this a useful resource for cooking or heating (production of hot water or steam) in the residential sector or in small commercial and public buildings that require a high-quality fuel in small-scale equipment without advanced controls and gas cleaning technologies [35].

With regard to the branches with leaves, the leaves have a less favorable quality index, with BQI values of 5.77 and 6.57, respectively. These values are comparable to those obtained for sunflower stems and seeds (BQI 5.61). These resources also have high calorific values and low sulfur content, although the ash content is higher. According to the parameters established by the AENOR standard [36], these pruning residues could be employed for industrial purposes. This sector uses more robust technologies with automatic cleaning systems for gases and ashes (more details in the following section).

Therefore, the parameters (PQI) that most influence the quality of avocado biomass are ash content, sulfur content, and moisture content. A high ash content, as is the case for the leaves, has logistical implications, such as potential contamination via soil or sand 
(no combustible components) during the collection of the biomass. This last point may be particularly relevant given that many different agrochemicals are traditionally used to grow this crop.

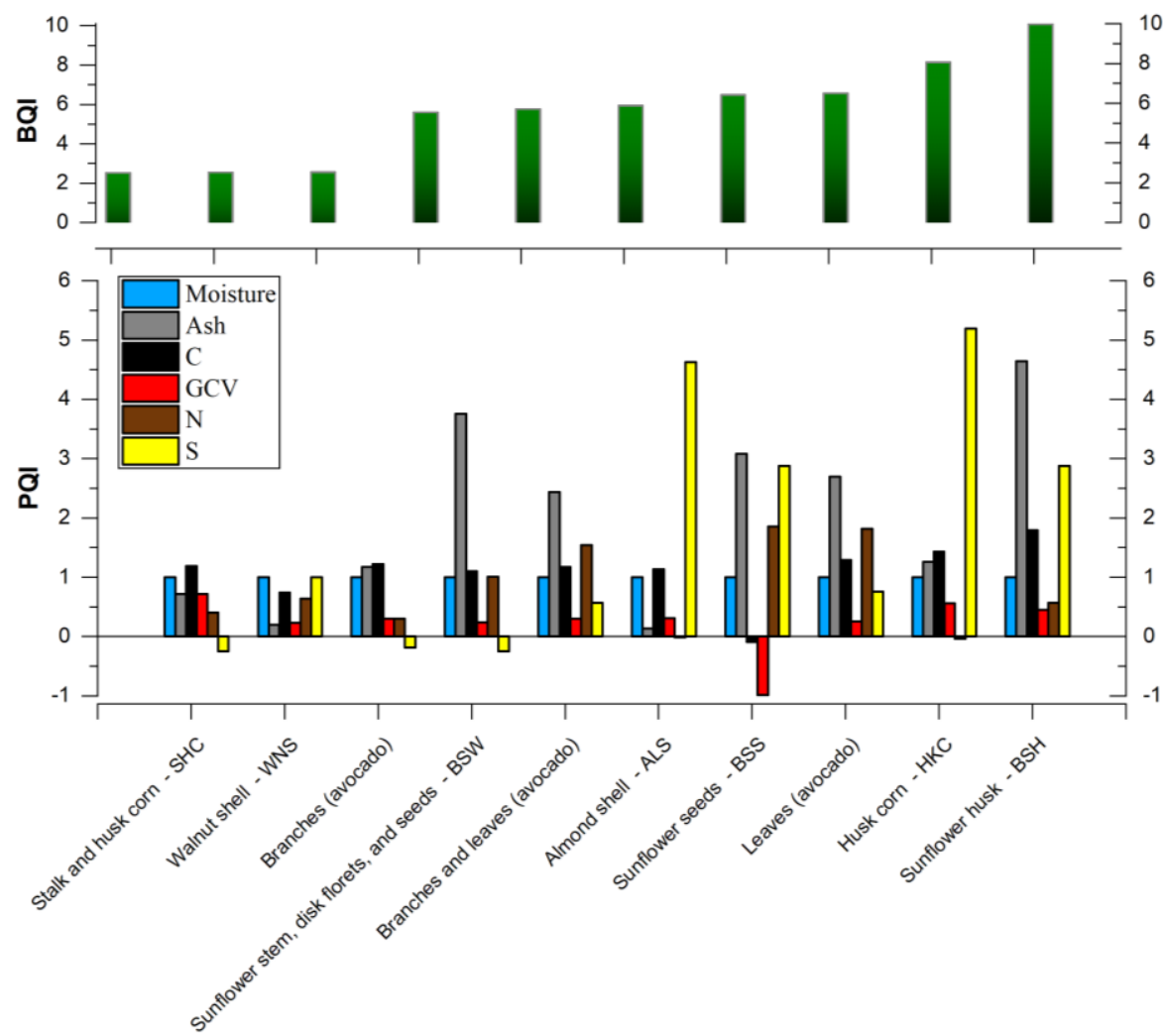

Figure 1. BQI ranking at fixed moisture content values (10\%) for avocado pruning biomass and reference indices taken from [23].

The sensitivity analysis reveals how the general biomass quality index (BQI) increases with increased moisture content, while holding all other parameters constant. Therefore, moisture content reduces the quality of biomass as a biofuel. Figure 2 shows that the mean moisture content of pruning residues collected in the field $(70 \%)$ produces BQI values greater than 10, making them highly unsuitable for energy use. However, air-drying the pruning residues would reduce their moisture content below $30 \%$, improving their quality.

These results indicate that avocado pruning residues must undergo a drying process in order to improve their energy properties. In the study region, branches with diameters greater than $2.5 \mathrm{~cm}$ could be used as firewood in the residential sector. However, more research would be needed to establish the presence of harmful agrochemical components, which may be released during the combustion process. On the other hand, if moisture content is reduced to $10 \%$, these branches could be pelleted and used domestically for heating. According to an economic study by [37], pellets could be sold for around 10.0 USD $\mathrm{GJ}^{-1}$ in the northern region of Mexico, where there is an imminent market for pellets to be used in efficient heaters and to substitute liquefied petroleum (LP) gas. Monetary values in this study are expressed in constant year 2021 US dollars.

With a moisture content of $30 \%$, branches and leafy branches could be used to make woodchips for small- and medium-sized boilers for industrial applications, which have automatic ash-cleaning systems and can control combustion temperature to avoid fouling. In the study region, woodchips can be sold for $2.2 \mathrm{USD} \mathrm{GJ}^{-1}$ (price in the current market). Potential buyers would include local industries that use oil or LP gas in small- and medium-sized boilers to generate process steam (e.g., agave distilleries). 


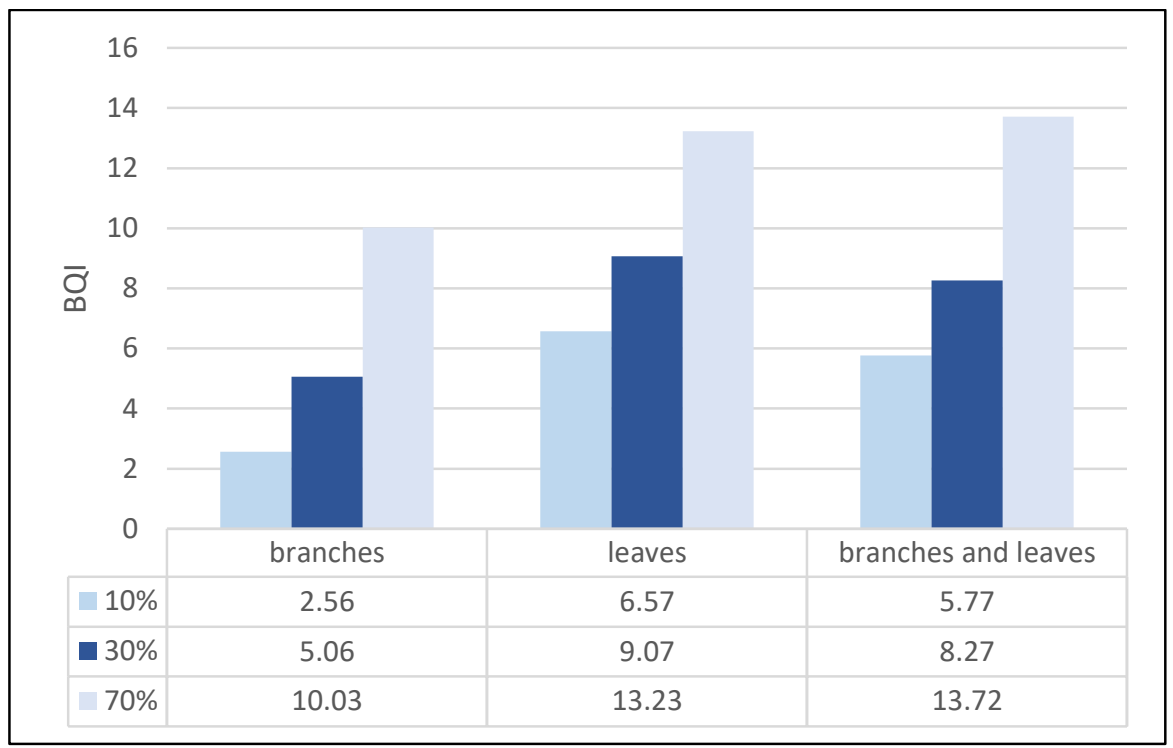

Figure 2. Sensitivity and variation of the $B Q I$ with increasing moisture content.

The average price of delivered fuel oil per mean energy unit is $7.7 \mathrm{USD} \mathrm{GJ}^{-1}$, higher than the cost of woodchips. A small boiler (75 kW of power) consumes on average 130,000 L of fuel oil, which is equivalent to 290 tons of biomass per year; it could be generated by residues from regular maintenance pruning of 22 trees (13 $\mathrm{kg}^{\text {tree }}{ }^{-1} \mathrm{DM}$; Section 3.2). This presents an opportunity for producers from rural communities to revalorize pruning residues. In order to grow this market, however, it would be necessary to offer training workshops and link producers with potential biomass users so as to estimate the size of the biomass market and determine delivery costs in the medium and long term. This would ensure a biomass supply for users and reduce the uncertainty that has clouded biomass trade in Mexico.

It is important to note that a mean leaf mass index of 1.4 was obtained. This means that light pruning will produce approximately $60 \mathrm{~kg}$ (42.7 kg times 1.4) of leaves per tree-year, or $40 \%$ of the total weight of the pruning residues, while for rejuvenation pruning, this can be as high as $12.5 \mathrm{~kg}$ tree-year $^{-1}$ ( $50 \%$ of total pruning weight). This shows that there is a large amount of leaf biomass that could potentially be used. However, the relatively high ash and sulfur contents of leaves, as well as their low bulk density, make them less suitable for energy purposes.

With regard to ash content, this can negatively influence the calorific value, and its role is carefully considered during the design of thermal technologies for use with solid biofuels [32]. Ash content is known to be one of the factors that determine the quality and potential use of biomass as a solid biofuel [28]. The use of certain types of biomass in boilers can lead to slagging and reduced equipment efficiency due to the alkali, sulfur, and silicon contents of ash [38]. Considering this parameter and the total BQI obtained, avocado branches would be the best resource for energy use, as they can be processed into woodchips or pellets for automated industrial boilers.

The energy use of biomass residues can stimulate rural development [39]. It could represent a source of employment and lead to social and economic benefits, as well as energy independence in rural communities [40]. However, given the high dispersal of orchards and the residues they generate, it would be necessary to organize small producers into groups or regions in order to facilitate the tasks of collecting and conditioning the pruning residues. Promoting the use of pruning residues for additional income generation could entail the very real risk of indirectly encouraging an increase in the amount of land devoted to avocado cultivation, leading to uncontrolled land-use change and the corresponding socioenvironmental impacts, including on biodiversity. Strict regulations and monitoring would be required in order to avoid bad practices, such as bureaucratic corruption. 
The information presented here can assist producers, social organizations, businesses, and decision makers in energy planning at the regional level. Furthermore, our results could assist in the crafting of public policies at the local level to promote the use of pruning residues from certified producers, thereby avoiding open biomass burning. It is important to underline that any strategy for the promotion and use of pruning residues must prioritize and ensure the protection and care of native forests.

\section{Conclusions}

Deriving two allometric equations to relate harvested pruning residues from avocado trees in orchards to crown diameter and tree height, we estimated the amount of biomass generated per hectare and revalorized its potential end uses. The mean biomass harvested from light to intensive pruning is $42.7 \mathrm{~kg}$ per tree per year. Rejuvenation pruning generates more pruning residues (187.7 kg per tree), but amounts to $25.1 \mathrm{~kg}$ per tree per year if we consider an average of 7.5 years between each pruning. Accounting for the moisture content and mean orchard density, residual biomass outputs of $1324 \mathrm{~kg} \mathrm{ha}^{-1}$ and $780 \mathrm{~kg} \mathrm{ha}^{-1} \mathrm{DM}$ year for each pruning method were obtained. The obtainable energy would be 26.2 to 15.4 GJ ha ${ }^{-1}$.

The flexibility of the parameter quality index (PQI) makes it possible to select evaluation criteria based on the most relevant parameters for the proposed end use. This allows us to directly compare parameters and the overall biomass quality index (BQI). We evaluated some of the most relevant parameters for calculating the BQI for woody and nonwoody biomass.

Moisture content is a highly relevant factor that negatively influences the BQI. The use of avocado pruning residues as energy would require them to undergo a drying process to reduce their moisture content below 30\%. According to the thermochemical properties of pruning residues, large-diameter branches have the best characteristics for energy use, mainly in low-power technologies. Branches have a high calorific value, as well as low ash and sulfur contents, unlike leaves, which increase the ash content of biomass and can affect the functioning of end-use technologies.

The limitations of the present study are: the allometric equations were calculated from a small sample of trees and orchards; we did not establish the presence of harmful agrochemical components in pruning residues, which may be released during the combustion process; and we did not perform a detailed analysis of the costs of production and logistical details for each type of biofuel (firewood, woodchips, pellets). In order to revalorize pruning residues and stimulate rural development by generating employment and favoring the energy independence of rural communities, it would be necessary to organize small producers into groups in order to facilitate the collection and conditioning tasks.

Author Contributions: Conceptualization, R.T., S.M., and B.V-M.; methodology, R.T., V.M.R.-G., S.R.-V., J.A.S.-G., M.R., and R.M.-B.; software, M.R.; validation, M.R. and R.M.-B.; formal analysis, R.T. and C.A.-A.; investigation, R.T., B.V.-M., and S.M.; writing-original draft preparation, R.T.; writing-review and editing, R.T., O.M., and C.A.-A.; visualization, J.A.S.-G.; supervision, B.V.-M.; project administration, C.A.-A.; funding acquisition, S.M. All authors have read and agreed to the published version of the manuscript.

Funding: This work was funded by the program PAPIIT-N223518, “Application of organophosphate pesticides in avocado orchards at Tingambato, Michoacán: Environmental and social determinants of health", and the DGAPA-UNAM postdoctoral fellowship program. Publication of this paper was funded by the Programa Iberoamericano de Ciencia y Tecnología para el Desarrollo (CYTED) through the Red Iberoamericana de Tecnologías de Biomasa y Bioenergía Rural (ReBiBiR-T).

Institutional Review Board Statement: Not applicable.

Informed Consent Statement: Not applicable.

Data Availability Statement: Not applicable. 
Acknowledgments: We would like to thank Andrea Alatorre for providing language help and writing assistance and Romeo A. Saldaña-Vázquez for his statistical analysis support. We also would like to acknowledge the grant Programa de Becas Posdoctorales (DGAPA) from UNAM (2021-2022).

Conflicts of Interest: The authors declare no conflict of interest.

\begin{tabular}{|c|c|}
\hline \multicolumn{2}{|c|}{ Abbreviations } \\
\hline \multicolumn{2}{|c|}{ The following abbreviations are used in this manuscript: } \\
\hline Bw & percentage of woody biomass in branches \\
\hline $\mathrm{Bl}$ & percentage of leafy biomass in branches \\
\hline $\mathrm{ml}$ & biomass of branches with leaves \\
\hline mw & biomass with no leaves \\
\hline Dt & tree trunk diameter at the height of the first branch \\
\hline $\mathrm{H}$ & total tree height \\
\hline Hc & crown height \\
\hline Dc & crown diameter \\
\hline $\mathrm{HHV}$ & superior calorific value \\
\hline BQI & general biomass quality index \\
\hline PQI & parameter quality index from a specific biomass \\
\hline $\mathrm{DM}$ & dry matter \\
\hline SD & standard deviation \\
\hline GJ & gigajoule \\
\hline
\end{tabular}

\section{References}

1. Tauro, R.; Serrano-Medrano, M.; Masera, O. Solid biofuels in Mexico: A sustainable alternative to satisfy the increasing demand for heat and power. Clean Technol. Environ. Policy 2018, 20, 1527-1539. [CrossRef]

2. Velázquez-Martí, B.; Cazco-Logroño, C. Structure analysis and biomass models for plum tree (Prunus Domestica L.) in Ecuador. Exp. Agric. 2017, 54, 1-9. [CrossRef]

3. SIAP-Servicio de Información Agroalimentaria y Pesquera, Gobierno de México. 2020. Available online: http:/ /infosiap.siap.gob. $\mathrm{mx} /$ gobmx/datosAbiertos_a.php (accessed on 8 December 2021).

4. Fu, T.; Ke, J.H.; Zhou, S.; Xie, G.H. Estimation of the quantity and availability of forestry residue for bioenergy production in China. Resour. Conserv. Recycl. 2020, 162, 104993. [CrossRef]

5. Velázquez-Martí, B.; Fernández-González, E.; López-Cortes, I. Salazar-Hernández DM. Quantification of the residual biomass obtained from pruning of vineyards in Mediterranean area. Biomass Bioenergy 2011, 35, 3453-3464. [CrossRef]

6. Velázquez-Martí, B.; Fernández-González, E.; López-Cortes, I. Salazar-Hernández DM. Quantification of the residual biomass obtained from pruning of trees in Mediterranean olive groves. Biomass Bioenergy 2011, 35, 3208-3217. [CrossRef]

7. Velázquez-Martí, B.; Fernández-González, E.; López-Cortes, I.; Salazar-Hernández, D.M. Quantification of the residual biomass obtained from pruning of trees in Mediterranean almond groves. Renew. Energy 2011, 36, 621-626. [CrossRef]

8. Estornell, J.; Velázquez-Martí, B.; López-Cortés, I.; Salazar, D.; Fernández-Sarría, A. Estimation of wood volume and height of olive tree plantations using airborne discrete-return lidar data. GISci. Remote Sens. 2014, 51, 17-29. [CrossRef]

9. del Mar Contreras, M.; Romero, I.; Moya, M.; Castro, E. Olive-derived biomass as a renewable source of value-added products. Process. Biochem. 2020, 97, 43-56. [CrossRef]

10. Velázquez-Martí, B.; Fernández-González, E. The influence of mechanical pruning in cost reduction, production of fruit, and biomass waste in citrus orchards. Appl. Eng. Agric. 2010, 26, 531-540. [CrossRef]

11. Velázquez-Martí, B.; Fernández-González, E.; López-Cortés, I.; Callejón-Ferre, A.J. Prediction and evaluation of biomass obtained from citrus trees pruning. J. Food Agric. Environ. 2013, 11, 1485-1491.

12. García-Vargas, M.C.; Contreras, M.D.M.; Castro, E. Avocado-derived biomass as a source of bioenergy and bioproducts. Appl. Sci. 2020, 10, 8195. [CrossRef]

13. Sokal, R.R.; Rohlf, F.J. Biometry: The Principles and Practice of Statistics in Biological Research, 4th ed.; W.H. Freeman and Company: New York, NY, USA, 2012; p. 937. ISBN 0-7167-8604-4.

14. Ricker, M. Solving linear regression without skewness of the residuals' distribution. Commun. Stat. Simul. Comput. 2021, 50, 2482-2495. [CrossRef]

15. UNE-EN 18134-1; Determination of Moisture Content-Method of Oven Drying-Part 1: Total Humidity. AENOR: Madrid, Spain, 2010. Available online: https:/ / www.en-standard.eu/une-en-iso-18134-1-2016-solid-biofuels-determination-of-moisturecontent-oven-dry-method-part-1-total-moisture-reference-method-iso-18134-1-2015/ (accessed on 30 January 2022). 
16. UNE-EN ISO 18122; Method for the Ash Content Determination. AENOR: Madrid, Spain, 2015. Available online: https: / / www.en-standard.eu/une-en-iso-18122-2016-solid-biofuels-determination-of-ash-content-iso-18122-2015/ (accessed on 30 January 2022).

17. ASTM E872-82; Standard Test Method for Volatile Matter in the Analysis of Particulate Wood Fuels. ASTM International: West Conshohocken, PA, USA, 2013. Available online: https://www.techstreet.com/standards/astm-e872-82-2019?product_id=2042233 (accessed on 30 January 2022).

18. Rutiaga-Quiñones, J.G.; Pintor-Ibarra, L.F.; Orihuela-Equihua, R.; Gonzalez-Ortega, N.; Ramírez-Ramírez, M.A.; Carrillo-Parra, A.; Navarrete-García, M.A.; Ruíz-Aquino, F.; Rangel-Méndez, J.R.; Hernández-Solís, J.J.; et al. Characterization of Mexican waste biomass relative to energy generation. BioResources 2020, 15, 8529-8553. [CrossRef]

19. 993.13-1996; Test Method: Nitrogen (Total) in Fertilizers. Combustion Method. AOAC: Rockville, MD, USA, 1997. Available online: http:/ / www.aoacofficialmethod.org/index.php?main_page=product_info\&products_id=561 (accessed on 30 January 2022).

20. UNE-EN 18125; Solid Biofuels-Determination of Calorific Value. AENOR: Madrid, Spain, 2018. Available online: https: / / www.en-standard.eu/une-en-iso-18125-2018-solid-biofuels-determination-of-calorific-value-iso-18125-2017/ (accessed on 30 January 2022).

21. Cherney, J.H.; Verma, V.K. Grass pellet Quality Index: A tool to evaluate suitability of grass pellets for small scale combustion systems. Appl. Energy 2013, 103, 679-684. [CrossRef]

22. Rocha, S.; Candia, O.; Valdebenito, F.; Espinoza-Monje, J.F.; Azócar, L. Biomass quality index: Searching for suitable biomass as an energy source in Chile. Fuel 2020, 264, 116820. [CrossRef]

23. Vasileiadou, A.; Zoras, S.; Iordanidis, A. Fuel Quality Index and Fuel Quality Label: Two versatile tools for the objective evaluation of biomass/wastes with application in sustainable energy practices. Environ. Technol. Innov. 2021, 23, 101739. [CrossRef]

24. Paniagua, S.; Reyes, S.; Lima, F.; Pilipenko, N.; Calvo, L.F. Combustion of avocado crop residues: Effect of crop variety and nature of nutrients. Fuel 2021, 291, 119660. [CrossRef]

25. Medina, P.; Berrueta, V.; Cinco, L.; Ruiz-García, V.; Edwards, R.; Olaya, B.; Schilmann, A.; Masera, O. Understanding household energy transitions: From evaluating single cookstoves to "clean stacking" alternatives. Atmosphere 2019, 10, 693. [CrossRef]

26. Ruiz-García, V.M.; Edwards, R.D.; Ghasemian, M.; Berrueta, V.M.; Princevac, M.; Vázquez, J.C.; Johnson, M.; Masera, O.R. Fugitive emissions and health implications of plancha-type stoves. Environ. Sci. Technol. 2018, 52, 10848-10855. [CrossRef]

27. Compressed Wood or Compressed Bark in Natural State-Pellets and Briquettes, Requirements and Test Specifications. In ÖNORM M 7135; The Pellet Handbook, Earthscan: London, UK, 2000.

28. Rodríguez, J.L.; Álvarez, X.; Valero, E.; Ortiz, L.; de la Torre-Rodríguez, N.; Acuña-Alonso, C. Influence of ashes in the use of forest biomass as source of energy. Fuel 2021, 283, 119256. [CrossRef]

29. Velázquez-Martí, B.; Gaibor-Cházvez, J.; Niño-Ruiz, Z.; Narbona-Sahuquillo, S. Complete characterization of pruning waste from the lechero tree (Euphorbia laurifolia L.) as raw material for biofuel. Renew. Energy 2018, 129, 629-637. [CrossRef]

30. Martín-Lara, M.A.; Ronda, A.; Zamora, M.C.; Calero, M. Torrefaction of olive tree pruning: Effect of operating conditions on solid product properties. Fuel 2017, 202, 109-117. [CrossRef]

31. Taylor, M.J.; Alabdrabalameer, H.A.; Michopoulos, A.K.; Volpe, R.; Skoulou, V. Augmented Leaching Pretreatments for Forest Wood Waste and Their Effect on Ash Composition and the Lignocellulosic Network. ACS Sustain. Chem. Eng. 2020, 8, 5674-5682. [CrossRef]

32. Morales-Máximo, M.; García, C.A.; Pintor-Ibarra, L.F.; Alvarado-Flores, J.J.; Velázquez-Martí, B.; Rutiaga-Quiñones, J.G. Evaluation and Characterization of Timber Residues of Pinus spp. as an Energy Resource for the Production of Solid Biofuels in an Indigenous Community in Mexico. Forests 2021, 12, 977. [CrossRef]

33. Obernberger, I.; Brunner, T.; Bärnthaler, G. Chemical properties of solid biofuels—significance and impact. Biomass Bioenergy 2006, 30, 973-982. [CrossRef]

34. Suriyati, B.S.; Julie, P.F.; Tooran, K.S.; Zsuzsa, S.; Brian, B.H.; Helge, E.; Nikolai, D.M.; Peter, A.J.; Peter, G.; Kim, D.J. Release of Chlorine and Sulfur during Biomass Torrefaction and Pyrolysis. Energy Fuels 2014, 28, 3738-3746. [CrossRef]

35. Biocombustibles Sólidos. Especificaciones y Clases de Combustibles. Parte 5: Clases de Leña de Madera. ISO 17225-5:2014; AENOR: Madrid, Spain, 2014. Available online: https://www.en-standard.eu/une-en-iso-17225-5-2014-solid-biofuels-fuelspecifications-and-classes-part-5-graded-firewood-iso-17225-5-2014/ (accessed on 30 January 2022).

36. Biocombustibles Sólidos. Especificaciones y Clases de Combustibles. Cáscaras de Frutos. UNE-164004; AENOR: Madrid, Spain, 2014. Available online: https:/ / www.en-standard.eu/une-164004-2014-biocombustibles-solidos-especificaciones-y-clases-debiocombustibles-cascaras-de-frutos / (accessed on 30 January 2022).

37. Tauro, R.; García, C.A.; Skutsch, M.; Masera, O. The potential for sustainable biomass pellets in Mexico: An analysis of energy potential, logistic costs and market demand. Renew. Sustain. Energy Rev. 2018, 82, 380-389. [CrossRef]

38. Vega-Nieva, D.J.; Garcia-Maraver, A.; Ortiz, L. Slagging and fouling risks derived from the combustion of solid biofuels. WIT Trans. State Art Sci. Eng. 2015, 85, 137-147. [CrossRef]

39. Mindy, S.C.; Darius, M.A.; Claire, A.M.; David, S. The potential rural development impacts of utilizing non-merchantable forest biomass. For. Policy Econ. 2017, 74, 20-29. [CrossRef]

40. Amirante, R.; Bruno, S.; Distaso, E.; La Scala, M.; Tamburrano, P. A biomass small-scale externally fired combined cycle plant for heat and power generation in rural communities. Renew. Energy Focus 2019, 28, 36-46. [CrossRef] 